\title{
Unusual cause of constipation: sunflower seeds
} bezoar

Bezoars are accumulated foreign material that forms concretions in the gastrointestinal tract, inducing abdominal pain, constipation, obstruction, and even peritonitis. This case report describes a rare rectal bezoar in a healthy young woman who had recently consumed large quantities of sunflower seeds.

A 21-year-old healthy woman was admitted with abdominal pain, rectal pain, and constipation for 5 days which had not improved with laxatives. On admission, her vital signs were normal and examination revealed lower abdominal tenderness with no peritoneal signs. Rectal examination revealed tenderness and sharp debris. Laboratory tests and an abdominal X-ray were essentially normal. On further questioning, the patient reported consuming large quantities of sunflower seeds and shells in the past week. Flexible sigmoidoscopy revealed circumferential inflammation with impacted sunflower seeds in the anorectal area up to $10 \mathrm{~cm}$ in the rectum ( Fig. 1 a). Multiple attempts at removal with different modalities (including rectal overtube, net removal, snare removal, soap suds enema, and manual disimpaction) resulted in little success ( $\bullet$ Fig. 1 b) Laxatives were also ineffective. A rigid proctoscopy and examination under anesthesia were carried out with manual disimpaction of the large bezoar. The patient was given one smog enema to remove any residual sunflower husks. She did well and was discharged after 2 days. At 1 week follow-up, the patient reported normal bowel movements and had no complaints. Rectal bezoars from sunflower seed shells requiring disimpaction have been reported in children but are very rare in adults
$[1,2]$. The diagnosis is made by clinical history or imaging, such as computed tomography (CT) $[3,4]$. Treatment may be conservative with laxatives, manual or endoscopic disimpaction, or surgery for severe cases $[3,4]$. The present case is unusual in that the adult healthy patient had no risk factors for bezoar formation. Although rectal bezoars are rare, early diagnosis and treatment are essential in preventing more serious complications.

Endoscopy_UCTN_Code_CCL_1AD_2AB

Competing interests: None

\section{R. G. Lim¹, A. L. Rawlings ${ }^{2}$, \\ S. L. Schultz ${ }^{3}$, L. H. Bradley ${ }^{2}$,} H. T. Hammad ${ }^{1}$, M. L. Bechtold ${ }^{1}$

${ }^{1}$ Department of Internal Medicine, University of Missouri School of Medicine, Columbia, Missouri, USA

${ }^{2}$ Department of Surgery, University of Missouri School of Medicine, Columbia, Missouri, USA

${ }^{3}$ Providence Urgent Care, Columbia, Missouri, USA

\section{References}

1 Minty B, Kelly L. Rectal bezoars in children. CMAJ 2010; 182: E532

2 Purcell L, Gremse DA. Sunflower seed bezoar leading to fecal impaction. South Med J 1995; 88: 87-88

3 Yoon SS, Kim MS, Kang DY et al. A case of successful colonoscopic treatment of colonic obstruction caused by phytobezoar. J Korean Soc Coloproctol 2011; 27: 211-214

4 Bala M, Appelbaum L, Almogy G. Unexpected cause of large bowel obstruction: colonic bezoar. Isr Med Assoc J 2008; 10: 829-830
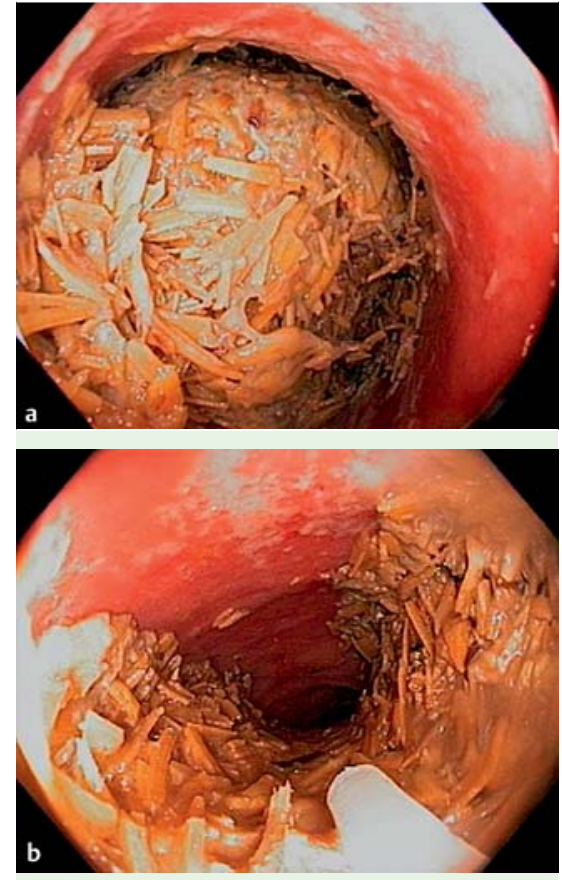

Fig. 1 The sunflower seed bezoar during flexible sigmoidoscopy: a at initial examination; and $\mathbf{b}$ after the first endoscopic treatment.

\section{Bibliography}

Dol http://dx.doi.org/

10.1055/s-0032-1325893

Endoscopy 2013; 45: E46

(c) Georg Thieme Verlag KG

Stuttgart · New York

ISSN 0013-726X

\section{Corresponding author}

\section{L. Bechtold}

Division of Gastroenterology

Five Hospital Drive, CE405

Columbia

MO 65212

U.S. A

Fax: +573-884-4595

bechtoldm@health.missouri.edu 